The definitive, peer-reviewed and edited version of this article is published and can be cited as

Santos, G. and J. Bhakar (2006), 'The Impact of the London Congestion Charging Scheme on the Generalised Cost of Car Commuters to the City of London', Transport Policy, Vol. 13, N¹, pp. 22-33. DOI: 10.1016/j.tranpol.2005.07.002

\title{
The impact of the London Congestion Charging Scheme on the generalised cost of car commuters to the City of London from a value of travel time savings perspective
}

\author{
Georgina Santos $^{1 *}$ and Jasvinder Bhakar ${ }^{2 * *}$ \\ ${ }^{1}$ Transport Studies Unit, University of Oxford, OX1 3QY, UK \\ ${ }^{2}$ Faculty of Economics, University of Cambridge, CB3 6DD, UK
}

\begin{abstract}
This paper shows that the impacts of the London Congestion Charging Scheme should not be analysed from the standard approach to value of travel time savings. This will invariably lead to the mistaken conclusion that drivers who value their travel time savings below the $£ 5$ congestion charge will be regarded as losers from the Scheme. The use of a simple expression of generalised costs leads to different conclusions. First, a motorist who continues to drive but values the time savings of the Scheme less than $£ 5$ can still gain from the scheme, if the generalised cost post-charging is lower than the generalised cost precharging. Second, a motorist who switches to the bus can still gain from the scheme. Since
\end{abstract}

\footnotetext{
${ }^{*}$ Corresponding author. Tel.: +44-1865-274-717; fax: +44-1865-515-194. E-mail address: Georgina.Santos@tsu.ox.ac.uk.

** Jasvinder Bhakar is now at Deutsche Bank in London.
} 
the bus travel time post-charging will typically be lower than the bus travel time precharging, it is possible that the generalised cost of a trip by car pre-charging will be higher than the generalised cost of a trip by bus post-charging, even after taking into consideration the inconvenience of switching.

\section{Key words}

Value of travel time savings, London Congestion Charging, road pricing

\section{Introduction}

Travel time savings undoubtedly constitute one of the main benefits that motorists can obtain as a result of any congestion charging scheme. How any given pre-charging motorist values these time savings is clearly an important determinant of the overall impact of the scheme on him or her. Having said this, this paper highlights that a more complete assessment of the impact of a congestion charging scheme on pre-charging motorists requires a broader use of values of travel time savings.

Essentially, if values of travel time savings are used to evaluate time savings, they should also be used to evaluate the cost of the time actually spent travelling. In the context of the London Congestion Charging Scheme, the standard approach to determining the effect of charging on a given individual that continues to drive in the zone, is to evaluate the car travel time savings received and compare them to the $£ 5$ toll. Similarly for an individual that switches to bus travel, the bus travel time savings would be evaluated and compared to the inconvenience of switching. These comparisons are not incorrect but they are not enough to determine whether the individual gains or loses as a result of the Scheme. Where possible, though, implications of the London Congestion Charging Scheme using this standard approach are derived, although only on the basis of aggregate data on car commuters to the City of London, an area entirely within the charging zone.

A revised, more complete, approach to using values of travel time savings in such an assessment is presented in this paper, and it is shown that the standard approach puts a negative slant on the predicted fate of both those that continue to drive and those that switch to bus travel. The practical relevance is examined, as far as possible, again in the context of the car commuters to the City of London. 


\section{Sources of variation of the value of travel time savings}

The theory underlying the value of a travel time saving is different depending on whether the individual receives it during or outside his or her working hours. However, in this paper, the emphasis will be on how individuals themselves value travel time savings. Strictly speaking, this value should be termed the individual, behavioural, or subjective value of travel time savings. However, for ease of exposition, the term value of travel time savings (VTTS) will be used, in all that follows, to specifically mean the amount an individual is willing to pay to save a unit of travel time, ceteris paribus, in a non-work context.

It is common practice in empirical work to apply a single VTTS to evaluate the monetary equivalent of a given travel time saving. By doing so, one implicitly assumes that marginal units of saved travel time are equally valued. In other words, the relevant individual's willingness to pay for a thirty minute travel time saving is equal to his or her willingness to pay for three separate (for example, on different days) ten minute travel time savings. Effectively, such use of a VTTS assumes that travel time savings are valued linearly. There is some evidence that confirms this. Small (1992) for example, reviews empirical studies on how small and how large time savings are valued, and concludes that such differences are negligible (p. 37, 38). Mackie et al (2003a) also state that 'a constant value per minute is more defensible than any alternative', including lower than average or zero values for small time changes (Section 3, point 27).

There are several sources of variation for the VTTS and these have been extensively studied, with the most comprehensive report being the one produced by Mackie et al (2003b).

One of the most widely recognised sources of VTTS variation is income. So long as the marginal utility of income is decreasing in income, individuals with higher incomes will have a higher VTTS, ceteris paribus. Other factors affecting the VTTS are travel mode and the conditions of travel in the relevant mode. For example, the marginal utility of travel time in a crowded and non-crowded bus, or in a car being driven at free-flow or congested conditions, for a given individual, may obviously differ, justifying the need for two different values of travel time savings. According to Mackie et al (2003a, Section 3, point 36) the VTTS for a given set of individuals are higher for bus relative to car, and lower for rail. Additionally, average VTTS on bus tends to be about half that on rail and car. The reason behind this is the different socio and income characteristics of the users of the different modes. 
Another source of variation is the purpose of the trip in question. Thus, one may be relatively unaffected by increasing travel time in a leisure journey, but may be significantly negatively impacted by increasing time in journeys where a specific arrival time is important, such as the journey to work.

\subsection{Empirical findings for the UK}

A recent and comprehensive source for values of travel time savings in the UK is the report to the Department for Transport by Mackie et al (2003b), mentioned above. This report reexamines a substantial stated preference data set used in an earlier investigation commissioned by the same department in 1994. Additionally, the results are crossreferenced with those obtained from meta-analysis. ${ }^{1}$ Table 1 details some of their recommended estimates.

Table 1: Estimates of the value of car travel time savings ${ }^{2}$ at end of 1997 values

\begin{tabular}{lcc}
\hline Income Band & Commuting (p/min) & Other $(\mathbf{p} / \mathbf{m i n})$ \\
\hline Below $£ 17,500$ & 3.6 & 4.6 \\
$£ 17,500-£ 35,000$ & 5.9 & 5.9 \\
Above $£ 35,000$ & 8.6 & 7.1 \\
\hline
\end{tabular}

Source: Mackie et al (2003a)

Note: p/min: pence per minute

Variation in the level of congestion essentially equates to a change in the specific nature of car travel, especially when considering drivers. This is a potentially prominent source of variation in a given individual's VTTS. MVA et al (1987) give an estimate of the relationship between congestion and value of time. In the presence of congestion, the latter could be increased by up to $40 \%$ and in very congested conditions the increase could be higher (MVA et al, 1987, p. 176). Additionally, Wardman (2001), after conducting a substantial meta-analysis ${ }^{3}$, concludes that time spent in congested traffic is valued $50 \%$ higher (p. 125). Further to that, a report produced by Steer Davies Gleave (2004), based on

\footnotetext{
${ }^{1}$ Statistical analysis that involves integrating results of many independent studies on the same issue.

${ }^{2}$ Mackie et al (2003, p.85) also suggest that these figures should be updated using the GDP/head level in the relevant period compared to 1997 , and an elasticity of 0.8 . This was the procedure used in the empirical analysis in Sections 4.3 and 4.4.

${ }^{3} 143$ UK studies produced between 1980 and 1996 were included.
} 
a stated preference exercise, concludes that in very heavily congested conditions motorists will put almost twice as much weight on their time, compared to free-flow conditions (p. 19).

\section{The London Congestion Charging Scheme}

The London Congestion Charging Scheme (LCCS) is essentially an area licensing scheme that covers an area of approximately $21 \mathrm{~km}^{2}$, representing $1.3 \%$ of the total $1,579 \mathrm{~km}^{2}$ of Greater London. The limit is defined by the Inner Ring Road. All vehicles entering, leaving, driving or parking on a public road inside the congestion charging zone (CCZ) between 7 AM and 6.30 PM Monday to Friday, excluding public holidays are charged $£ 5 .{ }^{4}$ No charge is made for driving on the Inner Ring Road itself.

The Scheme allows for a variety of exemptions and discounts. Exemptions include motorcycles and mopeds, emergency vehicles, buses and coaches with 9 or more seats, vehicles used by (and for) disabled persons, licensed London taxis and mini-cabs, certain military vehicles, and local government service vehicles (e.g. refuse trucks, street maintenance). Vehicles that can be registered to receive a $100 \%$ discount include alternative fuel vehicles (requires emission savings $40 \%$ above Euro IV standards) and roadside assistance vehicles. Residents can also register up to one car to receive a $90 \%$ discount.

The charge has to be paid in advance or on the day until 10 PM with late payment available between $10 \mathrm{PM}$ and midnight but with the charge rising to $£ 10$. The charge can be paid daily, weekly, monthly or yearly. The fine for non-payment is $£ 100$, reduced to $£ 50$ for prompt payment within 14 days. Failure to pay the penalty charge within 28 days results in the penalty being increased to $£ 150$.

A summary of the impacts of the LCCS are provided in the reports published by Transport for London (TfL) in June and October 2003, February and April 2004, and January 2005 (TfL, 2003a, 2003b, 2004a, 2004b, 2005). The three main facts that are specific to the present study are:

\footnotetext{
${ }^{4}$ On July 4, 2005 the charge was increased to $£ 8$. However, this paper was written before the charge was changed.
} 
- Congestion, as defined by $\mathrm{TfL}^{5}$, has undoubtedly fallen within the $\mathrm{CCZ}$ since the introduction of the Scheme.

- Predicted increased congestion in the area surrounding the CCZ has not materialised. LCCS' impact on congestion has thus been limited to the CCZ.

- Bus and car average speeds inside the CCZ have increased from $10.9 \mathrm{~km} / \mathrm{h}$ to $11.6 \mathrm{~km} / \mathrm{h}$ and $14.3 \mathrm{~km} / \mathrm{h}$ to $16.7 \mathrm{~km} / \mathrm{h}$ respectively ${ }^{6}$.

\subsection{Assessing the impact of congestion charging on motorists}

Introducing a congestion charge, equal to the marginal congestion cost at the efficient level of traffic flow, leads to the avoidance of a 'dead-weight loss', which in turn represents the net benefit to society as a whole. Rietveld and Verhoef (1998) make clear, however, that congestion pricing, according to traditional (first best) theory and assuming homogeneous individuals, makes all previous road users worse off, prior to revenue redistribution ${ }^{7}$.

To the extent that theoretical results of traditional first best congestion pricing theory provide a benchmark for the effects of real (second-best) congestion pricing schemes, the problem of road users being left worse-off highlights the importance of revenue allocation. Having said this, it is important to recognise that the LCCS is certainly not a perfect example of a congestion pricing scheme that traditional theory considers. ${ }^{8}$

The purpose of this section is to illustrate the sensitivity of the conclusions reached over this important issue with respect to how values of travel time savings are applied. In our terminology, the 'standard approach' refers to that conceptually adopted in several studies 9 where, at an individual level, the VTTS is used in discussions of who wins and who loses, only to evaluate time savings generated by the congestion pricing scheme. The appropriate value is then simply compared to the toll paid, if one continues to drive, or the (vaguely defined) 'inconvenience of changing mode', if one switches to a mode that has become

\footnotetext{
${ }^{5} \mathrm{TfL}$ defines the level of congestion, in $\mathrm{min} / \mathrm{km}$, as the actual travel rate minus the free-flow travel rate, assumed equal to the travel rate at night (TfL, 2003c, p.45).

${ }^{6}$ Car speeds were obtained from TfL (2003b). Bus data was provided on request from TfL and reflects average bus speeds for route sections inside the CCZ for sample periods before and after charging.

${ }^{7}$ By allowing for income heterogeneity across motorists, and the corresponding variation in their values of travel time savings, it has also been shown that this stark theoretical result changes slightly, in that some motorists (those with the highest values of travel time savings) may gain prior to revenue redistribution (Hau, 1992).

${ }^{8}$ For example, the congestion charge does not vary according to the level of congestion and the charge is the same regardless of vehicle type.

${ }^{9}$ Such as Gómez-Ibáñez (1992), Richardson and Bae (1998), Teubel (2000).
} 
quicker (Gómez-Ibáñez, 1992, p. 348) or cheaper in monetary terms. In either case, only if the valuation of the time saving exceeds the item it is being compared to, is the precharging motorist considered a winner.

As highlighted in Section 2, it is important to remember that values of travel time savings vary across several dimensions. Thus, values used in the analysis of the LCCS ought to be adjusted properly to reflect income levels, trip purpose, and, in the case of car travel, congested versus uncongested conditions, since these are the obvious sources of variation, in this context, for which we have empirical support.

In addition to the above, it is important to recognise that the VTTS is relevant not only to saved travel time but also to time that is actually spent travelling, and so embodies more information than the standard approach takes into account.

The implicit assumption made when using a single VTTS to give the monetary equivalent of a travel time saving is that such time savings are valued linearly. An individual's VTTS reveals what he or she is willing to pay for a marginal reduction in travel time. Clearly, this value is precisely equal to how costly that marginal unit of travel time was to this individual. For this reason, values of travel time savings can be used to both 'monetise' time savings, and derive the monetary equivalent of the time costs associated with travel itself.

The cost of a trip inside the CCZ before and after the LCCS will be different, not just because of the $£ 5$ toll, or the shorter travel time, but also because the disutility of the time spent in travel will be lower. The time saved is erroneously valued at the 'old' congested value in the standard approach. The value of travel time and time saved changes with levels of congestion and mode used, and this should be accounted for in the analysis.

In what follows, we seek to examine the importance of the variations in VTTS in the context of commuters to the CCZ, who previously travelled by car. The standard approach will be used first, to establish, as far as possible, the likely impact of the LCCS on these motorists. A 'revised approach', which represents a more complete utilization of the information in values of travel time savings, will then be used to analyze the same issue. 


\subsection{Data}

Our data consists of estimates from the Labour Force Survey ${ }^{10}$, provided by the Office of National Statistics, relevant to the periods Autumn 2002 and Autumn 2003, that detail the mode of travel to work and average incomes of commuters to the City of London that are resident in Greater London.

Although the average income in the City of London is higher than the average income anywhere else in the $\mathrm{CCZ}$, the data are still valid and useful for the purpose of this paper, which is to compare two different approaches to assessing the impacts of the LCCS from a value of time perspective.

The CCZ does not lie precisely within any well-established geographical areas. The City of London lies entirely in the CCZ. Despite its size (approximately $2.6 \mathrm{~km}^{2}$ ), in employment terms, the City of London is substantial, as $19.64 \%$ of all jobs located within the six main boroughs which comprise the $\mathrm{CCZ}^{11}$, are located within $\mathrm{it}^{12}$.

Data from several Greater London boroughs is excluded, however, where the details are prohibitively incomplete. Additionally, boroughs which have sections, geographically speaking, that lie in the CCZ are excluded since many of the City of London commuters resident in them may also be resident in the $\mathrm{CCZ}$ and therefore eligible to a $90 \%$ discount from the standard charge. The specific boroughs considered in this empirical analysis are therefore Haringey, Hackney, Tower Hamlets, Kensington \& Chelsea, Wandsworth, Brent, Merton, Bromley, Barking \& Dagenham, Redbridge, Havering, and Bexley.

This data are supplemented with data on car speeds as published in the different TfL reports (TfL, 2003a, 2003b, 2004a, 2004b, 2005) and bus speeds as provided by TfL on request. The fact that this does not chronologically correspond precisely with Autumn 2002 and 2003 is not a problem since the effects of LCCS have been broadly stable since its introduction. The use of aggregate data on speeds poses some limitation to the analysis, as there may be large variations by origin and destination and route taken. Having said that, we are not interested in a geographically detailed assessment of drivers that win or lose from the scheme according to the speed that prevails on the route that they choose. We are

\footnotetext{
${ }^{10}$ The sample size of this UK-wide survey is now about 60,000 households each quarter. However, estimates provided here are likely to be obtained from relatively small samples, meaning that results drawn from this data must be interpreted cautiously due to the potential problem of sampling error.

${ }^{11}$ These are the City of London, Camden, Lambeth, Islington, Southwark, and Westminster.

${ }^{12}$ The source of this information are the Economic Borough Profiles (2003), of the London Development Agency, which were provided by GLA Economics.
} 
rather more interested in the different conclusions that we can draw according to whether the VTTS are allowed to vary with traffic conditions or not.

\subsection{The standard approach to applying values of travel time savings}

The data shows that car commuting to the City of London by residents in the boroughs considered, fell by around $11.6 \%$ between Autumn 2002 and Autumn $2003^{13}$, which means that approximately $88.4 \%$ of these commuters pay the congestion charge.

In order to apply the standard approach, we need an estimate of how these commuters value the travel time savings generated by the LCCS. The average time saving is calculated on the basis of the change in average car speeds in the CCZ, which have increased from $14.3 \mathrm{~km} / \mathrm{h}$ to $16.7 \mathrm{~km} / \mathrm{h}$. We also assume that the average commuting trip to the City of London involves $5 \mathrm{~km}$ of travel in the charging zone ${ }^{14}$.

In light of the discussion earlier, Mackie et al (2003a) values of travel time savings estimates for car journeys with a commuting purpose are adjusted here to reflect that driving conditions in the CCZ prior to charging were very congested ${ }^{15}$.

Figure 1 depicts how the valuation of the estimated car travel time saving (which is doubled to reflect a return journey) compares to the charge paid for commuters with different weekly incomes. ${ }^{16}$

\footnotetext{
${ }^{13}$ Differences in total number of commuting trips (by all modes) made in the two periods are accounted for by re-weighting the Autumn 2002 figures to make the two years commensurate.

${ }^{14}$ The CCZ has a diameter of approximately $5 \mathrm{~km}$, yet roads are not perfect straight lines and the CCZ involves several 'one-way systems', which lengthen average trip distances.

${ }^{15}$ It is assumed that the VTTS in car travel is $50 \%$ greater in congested conditions. Mackie et al (2003) estimates are assumed to represent uncongested car travel. The estimates have also been updated using GDP/capita data for the UK (2001) and applying the suggested elasticity of 0.8 , following the recommendations by Mackie et al (2003, p. 85, R10).

${ }^{16}$ A simple interpolation procedure was applied to Mackie et al (2003) VTTS estimates from Table 1 above to obtain sufficiently detailed income differentiated values of travel time savings.
} 


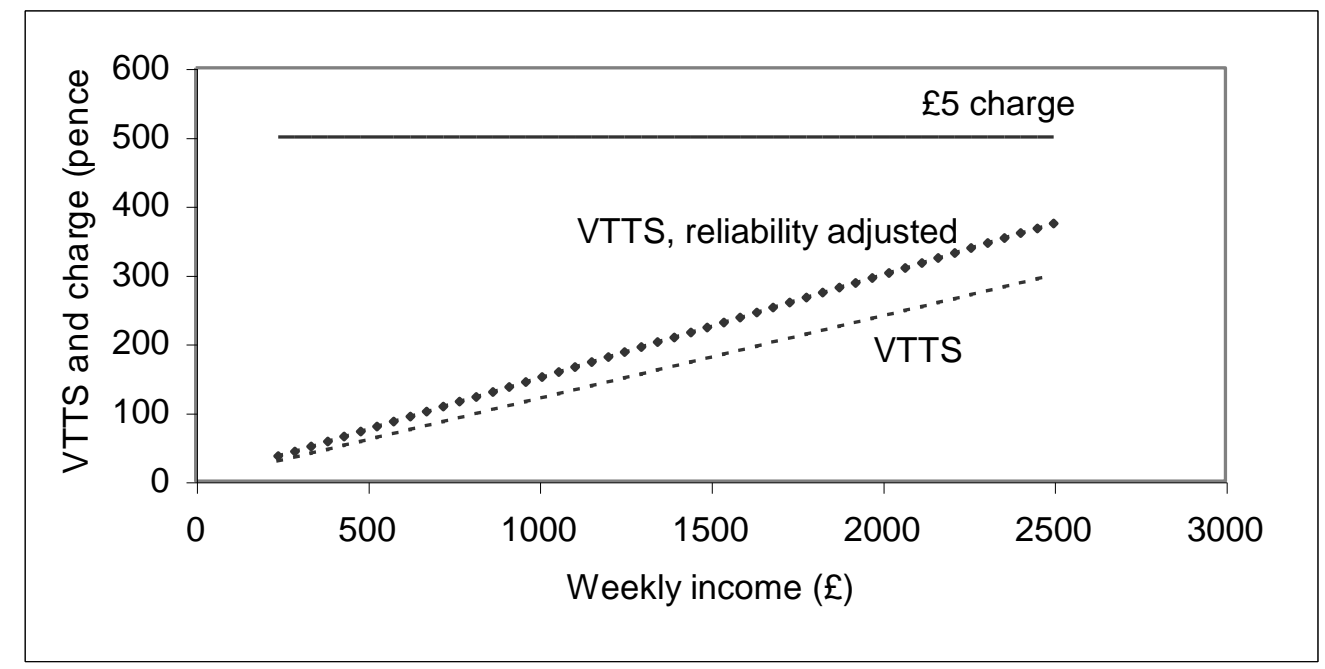

Figure 1: Standard approach, assuming travel distance $=5 \mathrm{~km}$

The average weekly income of those working in the City of London is $£ 812$, and this increases to $£ 926$ when we consider only those commuters who in Autumn 2003 travelled by car. Given these incomes it is evident, from the diagram above, that essentially no commuter will value the time savings more than the $£ 5$ charge.

Proponents of the LCCS may, in light of this, argue that commuters also benefit from journey time reliability improvements.

As of March 2005, the Transport Analysis Guidance provided by the UK government (Department for Transport, 2004a), does not include reliability impacts. They claim that the reason for this is that the methods of estimating these are not well developed yet. ${ }^{17} \mathrm{We}$ believe that although there is room for improving the techniques used for estimating the value of an increase in reliability, there is already enough evidence to allow us to introduce it in our analysis.

Lam and Small (2001) measure values of time and reliability from 1998 data on actual behaviour of commuters on State Route 91 in Orange County, California, where they choose between a free and a variably tolled route. They find that the value of reliability is $66 \%$ of the VTTS for men, and of $140 \%$ of the VTTS for women in their sample. ${ }^{18}$ Brownstone and Small (2005) conduct a comparative study where they include the results

\footnotetext{
${ }^{17}$ The DfT also says that they expect to publish advice in the near future which will enable monetised estimates of reliability impacts to be derived for some studies (Department for Transport, 2004a, TAG Unit 3.5.4).

${ }^{18}$ They explain this difference may be attributed to the fact that women have more child-care responsibilities, and therefore less scheduling flexibility.
} 
of Lam and Small (2001) as well as the results of other studies of the scheme on State Route 91 and another scheme on the Interstate 15. They conclude that when satisfactorily identified, reliability is valued quite highly. However, they identify substantial heterogeneity in these values across the population, and find it difficult to isolate its exact origins.

Table 3 of the Six Months On report (TfL, 2003b) implies reliability benefits of $12 \%$ above the time benefits when buses are included, and of $7.4 \%$ when buses are excluded.

Dodgson et al (2002) argue that reliability benefits amount to, on average, one quarter of time saving benefits.

It is clear that there is no widely accepted methodology for estimating reliability benefits, let alone an accepted value as a percentage of the time benefits. Nonetheless we can revise the basic result of the standard approach by adjusting the VTTS by $25 \%$, as suggested by Dodgson et al (2002). The main conclusion remains unchanged, as shown in Figure 1. In all likelihood, effectively no pre-charging car commuters would be classified as winners using the standard approach. ${ }^{19}$ It is important to note that there are obviously many simplifications being made in this analysis. For example, the possibility that an individual gains additional time savings from other trips made in the same day is ignored. Additionally, the issue of car-pooling is not considered. Cars with more than one occupant face a different trade off between time and money. If the congestion charge is paid by all the occupants, each paying an equal part, and the time savings are enjoyed by all, then the value of the time savings for all the trip makers in that car together stands a better chance of exceeding the $£ 5$ charge. The complication in this case arises from the fact that in general car passengers are assumed to have a lower VTTS. For example, Mackie et al (2003b) find that car passengers' VTTS are 20 to 25\% lower than car drivers' (p. 31). Having said that, their results for commuting are not significant, which they find reasonable given the small sample due to the majority of car commuters travelling alone. ${ }^{20}$ The Department for Transport (2004b) does not even give different values for car drivers and passengers except for working trips. If we assume that after the congestion charge some drivers switched to being passengers, and that there is no disutility from that change, then all occupants,

\footnotetext{
${ }^{19}$ Even adjusting by $140 \%$, which would obviously be an exaggeration, since the value only applies to women on State Route 91 in California, would result in that the minimum weekly wage needed to justify the $£ 5$ charge would be around $£ 2220$.

${ }^{20}$ Assuming all car commuters drive alone is therefore not unrealistic.
} 
passengers and driver, can be thought to have similar VTTS. In this case, the more occupants the car had, the more likely it would be for the total VTTS of all occupants together to exceed the congestion charge.

In this study however, it is simply assumed that all car commuters to the City of London drive alone. Ignoring any potential additional time savings from other trips made in the same day and car-pooling are justified simplifications, since the objective of this section is to highlight the effect that different approaches to applying values of travel time savings can have on these conclusions.

Of the estimated $11.6 \%$ that have switched, we only consider those that have switched to the bus. This simplification is supported by noting that the majority of those that switched from driving are likely to have switched to the bus. Pre and post charging vehicle counts, combined with average vehicle occupancy figures, indicate that out of the trip making which has generated the observed increases in the number of bicycles, motorcycles, taxis, and buses and coaches in the CCZ, 84\% can be associated with increased bus and coach patronage $^{21}$. Additionally, other modes of travel for commuting to the CCZ, such as London Underground and National Rail services, have seen no noticeable increases in patronage following congestion charging ${ }^{22}$. Alongside this, as shown later, much of the switching away from cars appears to have occurred amongst commuters to the City of London resident in Inner London boroughs, where switching to the bus is more plausible, compared to from Outer London boroughs, for obvious reasons.

Gómez-Ibáñez (1992) labels the outcome for individuals that switch to bus travel as uncertain, in the sense that it seems difficult to determine whether they win or lose from a congestion charging scheme. The source of this problem is undoubtedly the expression 'inconvenience of changing mode', which has no obvious value. There are studies that have, however, implied that such individuals are net losers, on grounds, usually, that

\footnotetext{
${ }^{21}$ Vehicle occupancy ratings, used in this calculation, were taken from the London Travel Report (2002) and Transport Economics Note (TEN). Gross vehicle counts from Spring 2002 and Spring 2003 (supplied by Transport for London) are provided in the appendix.

${ }^{22}$ Underground usage across London and specially in Fare Zone 1 decreased. The reason for this decrease is obviously not related to the LCCS in any way. If anything the congestion charge might have caused a marginal increase in demand. The reasons for the decrease in passenger levels on the London Underground are probably linked to the slowdown of the economy and the decrease in tourism in London, which in turn may be linked to the war in Iraq (TfL, 2003b). In addition to that, the Central Line was temporarily closed for almost three months following a derailment at Chancery Lane station in January. No significant changes in demand for trips by rail have resulted from the Scheme, and this is in line with TfL's expectations (TfL, 2003b).
} 
congestion pricing coerces modal switch ${ }^{23}$. The simple conclusion reached with the standard approach is therefore that nearly all pre-charging car commuters to the City of London are worse off as a consequence of the LCCS.

\subsection{The revised approach to applying values of travel time savings}

A basic concept used in transport analysis is that of generalised cost (GC). The expression below defines the generalised cost of a given individual making a particular trip. A trip is assumed to have a monetary cost (e.g. vehicle operating cost or bus fare) and a time cost, which can be expressed in monetary units, given a value of time. In the present study the VTTS is explicitly used to convert the time costs of a trip into their monetary equivalent ${ }^{24}$, under the assumption that time savings are valued linearly.

$$
\begin{array}{rl}
G C_{i}^{j}=m_{i}+b_{i}^{j} t_{i}^{j} & i=C, B \text { (indicating car or bus respectively) } \\
j & =1,2 \text { (indicating before and after charging respectively) }
\end{array}
$$

where $m_{i}$ is the (constant) monetary cost of $i, b_{i}^{j}$ is the VTTS specific to mode $i$ during period $j$ and $t_{i}^{j}$ is in-vehicle time of mode $i$ during period $j$. Walking and waiting time costs associated with car and bus travel are assumed to be constant and embodied in $m_{i \cdot}{ }^{25}$

We now make two propositions and assess them for practical relevance to the LCCS.

\section{Proposition 1}

A motorist who continues to drive (and pay the $£ 5$ congestion charge) but values the time savings of the LCCS less than $£ 5$ can still gain from the Scheme.

The idea behind this proposition is depicted graphically in Figure 2.

\footnotetext{
${ }^{23}$ Such as Santos and Rojey (2004, p. 5) and Litman (1999).

${ }^{24}$ Hensher (1997) supports the use of the behavioural VTTS in generalised cost functions.

${ }^{25}$ This assumption is obviously plausible for car travel and bus walking time. As for bus waiting times, data obtained from TfL on 'excess waiting time' (the difference between the observed average bus waiting time and the actual waiting time if all buses ran exactly to schedule) indicates that changes in actual bus waiting times are only in the order of one minute or less, assuming that 'scheduled bus waiting times' (data for which is unavailable) are unchanged.
} 


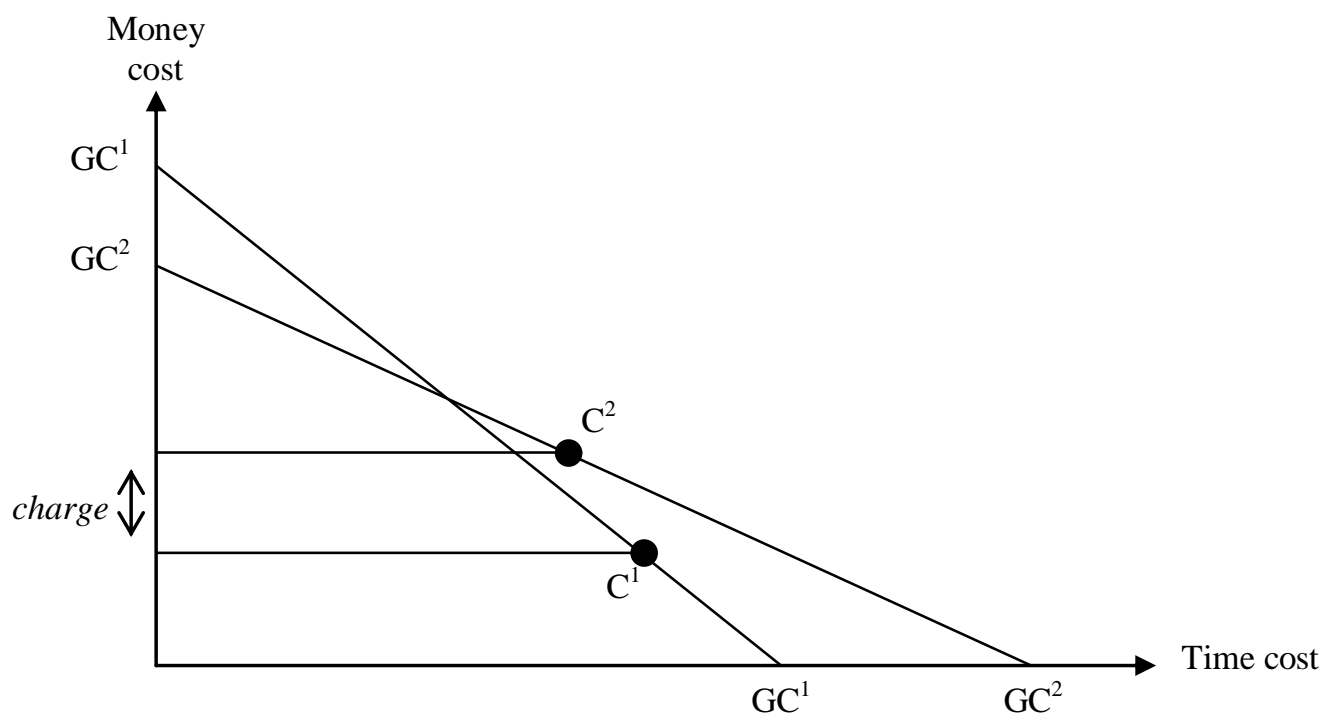

Figure 2: An example of GC before and after charging

The two components of the generalised cost of making a trip by car are depicted in the axes of Figure 2. These are the money cost, which includes the vehicle operating costs and the congestion charge if there is one, and the time cost, which is the time spent making the trip. The units on the y-axis, which gives the money cost, are pounds (or any other monetary unit) and the units on the $\mathrm{x}$-axis, which gives the time cost, are minutes (or seconds, or hours). Any trip will have a money cost and a time cost. The exact combination of these determines the location of the ordered pair (time, money). By using a VTTS the money component in monetary units can be translated into time cost in time units, and the time component in time units can be translated into money cost in monetary units. The intersections of the downward sloping lines on Figure 2 with the axes give the total generalised cost of a trip expressed either in monetary units (y-axis) or in times units ( $\mathrm{x}$ axis). The magnitude of the slope of these lines reflects the VTTS. The lines give the different combinations of the two components of the generalised cost that will give the same total generalised cost. Thus, they can be seen as travel budget constraints representing all the combinations of generalised cost components that result in a given level of generalised cost for a given trip. They are also indifference curves, as movement along either of the curves reflects how the individual is willing to trade-off car travel time for money. ${ }^{26}$ Needless to say, any combination of cost components that lies above an

\footnotetext{
${ }^{26}$ A real world example of this is the case where a driver wishes to travel from origin A to destination B. The (minimum) generalised cost of making such a trip is $\overline{G C}$. The driver will typically choose between different alternatives such as a long route where he can travel faster, thus raising the fuel cost but reducing the time
} 
indifference curve corresponds to a higher level of generalised costs (or a higher budget line).

When congestion charging is introduced, congestion will be lower and so the time component of the generalised cost will be lower. The money component of the generalised cost on the other hand, will be higher because there is a congestion toll to be paid in addition to the original money costs. As a result, the combination (time, money) will move north-west along the same indifference curve. However, if congested conditions are relieved, the value that drivers put on saving travel time will be lower. Therefore, VTTS will be lower, and so will be the slope of the new indifference curve in less congested conditions.

The characteristics of the car mode, for a particular trip, before and after congestion pricing, in terms of monetary cost and in-vehicle time cost, are given by its location in (money, time) space, $\mathrm{C}^{1}$ and $\mathrm{C}^{2}$, respectively. The north-westerly movement of $\mathrm{C}^{1}$ to $\mathrm{C}^{2}$, reflects the impact of congestion pricing. The magnitude of the slope of the lines passing through $\mathrm{C}^{1}$ and $\mathrm{C}^{2}$ reflect the VTTS of this individual for using a car before and after congestion pricing.

The VTTS is shown to fall across $\mathrm{C}^{1}$ and $\mathrm{C}^{2}$ as it is assumed that the VTTS for driving is higher in congested versus uncongested conditions, thus the indifference curve passing through $C^{1}$ is steeper than that passing through $C^{2}$. The individual's valuation of the time saving is depicted as below the congestion charge, since $\mathrm{C}^{2}$ is north-east of the initial indifference curve. The GCs associated with $\mathrm{C}^{1}$ and $\mathrm{C}^{2}$ are given by the intersection of the relevant indifference curve with the money-axis, since, at this point the entire time costs of the trip are converted into their monetary equivalent. Thus, although the charge is greater than the valuation of the time saving, it is evident that the GC of driving for this particular trip has fallen. Of course, the crucial assumption here is that, for a given time saving generated by the congestion pricing scheme, the VTTS in car travel falls sufficiently due to there being less congestion.

Having said this, the LCCS has only, as expected, reduced congestion inside the CCZ. Therefore, the VTTS of a given individual travelling by car can only be expected to fall for

cost, or a shorter, more congested route, where he will spend more time (perceived as more costly as well) in congested conditions, but less money in fuel (assuming the speed is constant enough for congestion not to raise the fuel cost), or alternatives in between these two extremes. Whatever route he chooses he will still bear $\overline{G C}$. However, the combinations of the components of the generalised cost will be different in each case. If the money and time components of the GC are perfect substitutes, the indifference curves are linear. 
that portion of the trip that is made inside the $\mathrm{CCZ}$, not its entirety, as pivoting the car indifference curve in Figure 2 assumes.

In terms of the LCCS, then, the proposition is more accurately illustrated as below:

$G C_{C}^{l}=m_{C}+b_{C}^{*} t+b_{C}^{1} t_{C}^{1}$

$G C_{C}^{2}=m_{C}+b_{C}^{*} t+b_{C}^{2} t_{C}^{2}+$ charge

$G C_{C}^{1}-G C_{C}^{2}=b_{C}^{1} t_{C}^{1}-b_{C}^{2} t_{C}^{2}-$ charge $=$

$b_{C}^{1}\left(t_{C}^{1}-t_{C}^{2}\right)+t_{C}^{2}\left(b_{C}^{1}-b_{C}^{2}\right)-$ charge

where $b_{C}^{*}$ is the VTTS for the portion of the car journey outside the CCZ, $b_{C}^{j}$ is the VTTS for the portion of the car journey inside the $\mathrm{CCZ}$ during period $j$ (before or after charging), $t$ is the time spent travelling from origin to the $\mathrm{CCZ}$ perimeter, $t_{C}^{j}$ is the time spent travelling inside the $\mathrm{CCZ}$ during period $j$ (before or after charging), and charge is the $£ 5$ congestion charge. $b_{C}^{*}$ and $t$ are assumed to be constant and the VTTS for the portion of the car journey inside the $\mathrm{CCZ}$ before charging is assumed to be greater than the one after charging, to reflect the impact of the congestion charging scheme $\left(b_{C}^{1}>b_{C}^{2}\right){ }^{27}$ Even when the time savings are valued below the congestion charge, it is still possible for $G C_{C}^{1}-G C_{C}^{2}>0$, implying a reduction in the GC of the same trip, so long as $b_{C}^{1}$ is sufficiently above $b_{C}^{2}$. In the last expression $b_{C}^{1}\left(t_{C}^{1}-t_{C}^{2}\right)$ represents the valuation of the time saving and $t_{C}^{2}\left(b_{C}^{1}-b_{C}^{2}\right)$ represents the reduction in cost of time still spent travelling.

The standard approach misses the crucial issue that even when an individual values the time savings received below the toll paid, by continuing to drive he or she additionally benefits from being able to do so in more desirable conditions as implied by the reduction in the VTTS, and can thus still benefit overall.

The question is whether this proposition has any practical relevance for the LCCS. Figure 3 reflects how commuters with different incomes would value the time savings generated by the Scheme compared to the $£ 5$ charge (just like Figure 2) together with $G C_{C}^{l}$ and $G C_{C}^{2}$ as defined above, but excluding the elements which have been assumed constant

\footnotetext{
${ }^{27}$ As explained in Section 2.3 the VTTS is higher with higher congestion.
} 
for simplicity. ${ }^{28}$ A 50\% premium is added to the VTTS for driving in congested conditions, in line with the findings presented in Section 2.1.

Figure 3 shows that Proposition 1 has real practical relevance for car commuters to the City of London with weekly incomes in excess of approximately $£ 1400 /$ week. Although this is not outside the conceivable range of incomes for the sample of City of London commuters, it implies that the proposition only 'converts' relatively few of the losers predicted by the standard approach into winners, and would certainly not 'convert' the average pre-charging commuter to the City of London. However, it does represent a significant improvement to the negative conclusions of the standard approach.

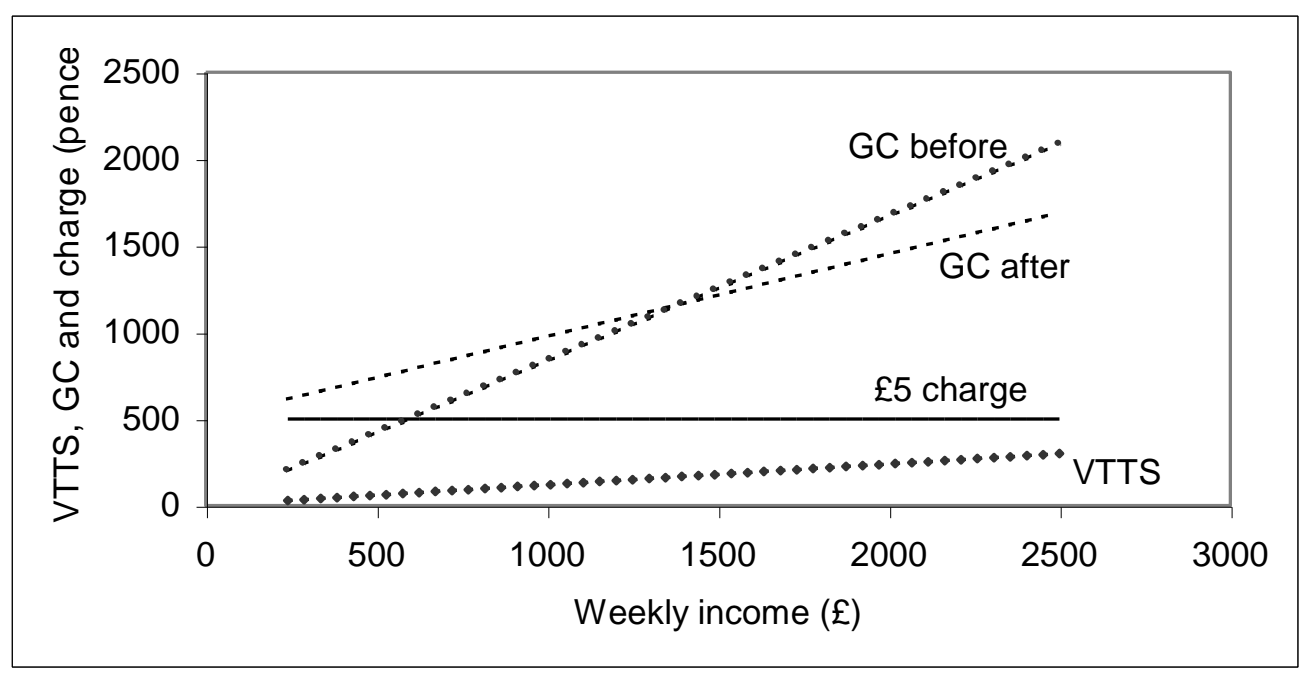

Figure 3: Revised approach, assuming travel distance $=5 \mathrm{~km}$

If the travel distance inside the CCZ were assumed to be $2.5 \mathrm{~km}$, which would perhaps be more realistic for the current $\mathrm{CCZ}$, the intersection of the GC curves would only occur at an income level of approximately $£ 2800 /$ week. If that were the case, virtually all drivers would be categorised as losers, even in the revised approach.

It is interesting to see what the outcome would be if there were an extension of the CCZ as is currently under consideration (Greater London Authority, GLA, 2004). Since the area of the zone would be almost doubled, the travel distance inside the extended CCZ may be assumed to be $9 \mathrm{~km}$.

\footnotetext{
${ }^{28}$ Ignoring the other elements of GC is justified assuming they are constant since, in this case, the income levels at which $G C_{C}^{1}-G C_{C}^{2}>0$, will be identical to those for which $b_{C}^{1} t_{C}^{1}>b_{C}^{2} t_{C}^{2}+$ charge.
} 
Figure 4 shows the results of the calculations. Before going any further, the numbers assumed deserve some attention. First, the average pre-charging speed of the new parts of the $\mathrm{CCZ}$ is assumed to be $15.4 \mathrm{~km} / \mathrm{h} .{ }^{29}$ Second, the percentage increase in average speed is assumed to be between $3 \%$ and $8 \%^{30}$, which at most amounts to half the one experienced in the original CCZ. This is because the reduction in traffic is very likely to be lower, in the order of $5 \%$ to $10 \%$ only. Some of the reasons to expect a lower decrease in traffic and increase in speed are: (a) around $30 \%$ of the potentially chargeable vehicles entering the area of the extension are already paying the charge because they use the original CCZ (TfL, 2004c, p.3); (b) the extension is 1.4 times more densely populated than the original CCZ (TfL, 2004c, p.2-3), (c) the extension has a greater proportion of car travel by residents and as result a higher proportion of households would be able to take advantage of a residents' discount (TfL, 2004c, p.3). Some residents that currently do not drive during charging hours may be attracted to the roads making use of their discount, with which they will be able to drive in the original CCZ.

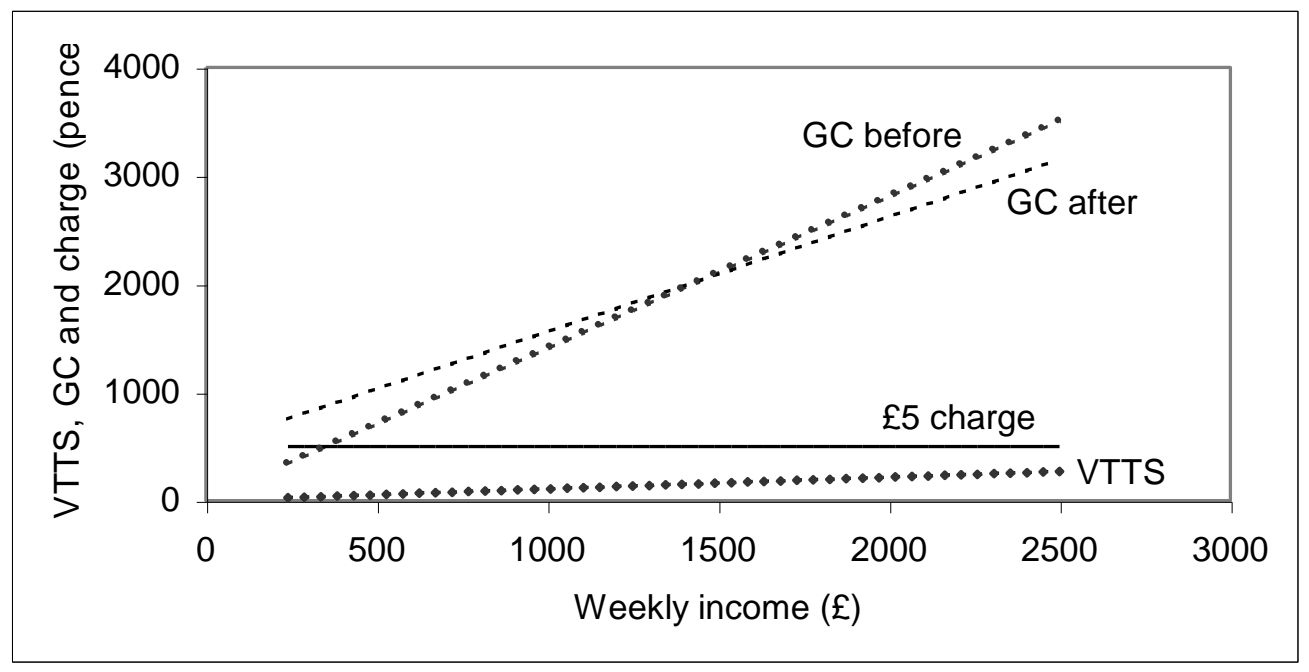

Figure 4: Revised approach, assuming travel distance $=9 \mathrm{~km}$

\footnotetext{
${ }^{29}$ This was computed using the congestion value of $2 \mathrm{~min} / \mathrm{km}$ reported in Annex E of the Report to the Mayor (TfL, 2004c, p.2). Since congestion is the difference between the average network travel rate and the uncongested (free-flow) network travel rate in minutes per veh-km, the new expected speed can be estimated. Using the uncongested network travel rate of $1.9 \mathrm{~min} / \mathrm{km}$ (approx. $32 \mathrm{~km} / \mathrm{h}$ ) from TfL (2003b, p.52), a 2 $\mathrm{min} / \mathrm{km}$ congestion gives a speed of $15.4 \mathrm{~km} / \mathrm{h}$.

${ }^{30}$ This is computed on the basis of the $10 \%$ to $20 \%$ expected reduction in congestion reported in Annex E of the Report to the Mayor (TfL, 2004c, p.9).
} 
Figure 4 assumes a 3\% increase in average speed in the extension. An $8 \%$ increase yields almost the same results (the weekly level of income at which the GC curves intersect is $£ 1450$ for a $3 \%$ average speed increase in the extension, and $£ 1325$ for an $8 \%$ ).

Pre and post charging speeds in the original CCZ are assumed as before ${ }^{31}$. Travel inside the extension will take place at a different speed than travel in the original CCZ. Levels of congestion will also be different. As a result, the VTTS assumed need to be different. Table 2 presents a summary of the figures used. The sensitivity of the results to the VTTS is discussed below.

Table 2: Speeds and VTTS assumed for the CCZ before and after extension

\begin{tabular}{lcccc}
\hline & \multicolumn{2}{c}{ Pre-charging } & \multicolumn{2}{c}{ Post-charging } \\
\hline & Speed & VTTS & Speed & VTTS \\
& $(\mathrm{km} / \mathrm{h})$ & weight & $(\mathrm{km} / \mathrm{h})$ & weight \\
Original CCZ & 14.3 & 1.5 & 16.7 & 1 \\
Extension zone & 15.4 & 1.4 & 15.9 & 1.2 \\
\hline
\end{tabular}

Source: Speeds in the original CCZ from TfL (2003b), speeds in the extension from TfL (2004c), VTTS weights assumed by the authors

Figure 3, which shows the results for the original CCZ is not too different from Figure 4, which shows the results for the extended CCZ. The minimum weekly income necessary for the GC to decrease is still around $£ 1400$.

An interesting issue, however, is brought to light if we assume different VTTS. If the weights assigned to the VTTS in the extension are equal to those in the original CCZ (1.5 for pre-charging and 1 for post-charging), then as the distance increases, the level of income at which the GC curves cross is much lower, and even reaches the actual average income of a car commuter to the City of London (£926).

This goes to show the sensitivity of the analysis to the VTTS, and the importance of the decision on what weights to apply to represent the mix of travel times, as rightly pointed out by Hensher and Goodwin (2004). With high VTTS, Proposition 1 would become very relevant. The longer the distances driven in less congested conditions, the greater the number of winners from the Scheme would be. In that case, increasing the size of the zone

\footnotetext{
${ }^{31}$ It is expected that there would be a slight increase in traffic in the original CCZ of between $1 \%$ and $2 \%$ (TfL, 2004c, p. 9) but the effect of this for our calculations is negligible and it shall therefore be ignored.
} 
would be a useful way to convert many of those who are otherwise losers into winners, and would constitute a useful compensating device in itself.

A potentially puzzling feature of the data is that a significant number of commuters especially from outer London boroughs appear to have switched to the car as a result of the LCCS. Figure 5 shows the percentage change in car commuting from different boroughs to the City of London.

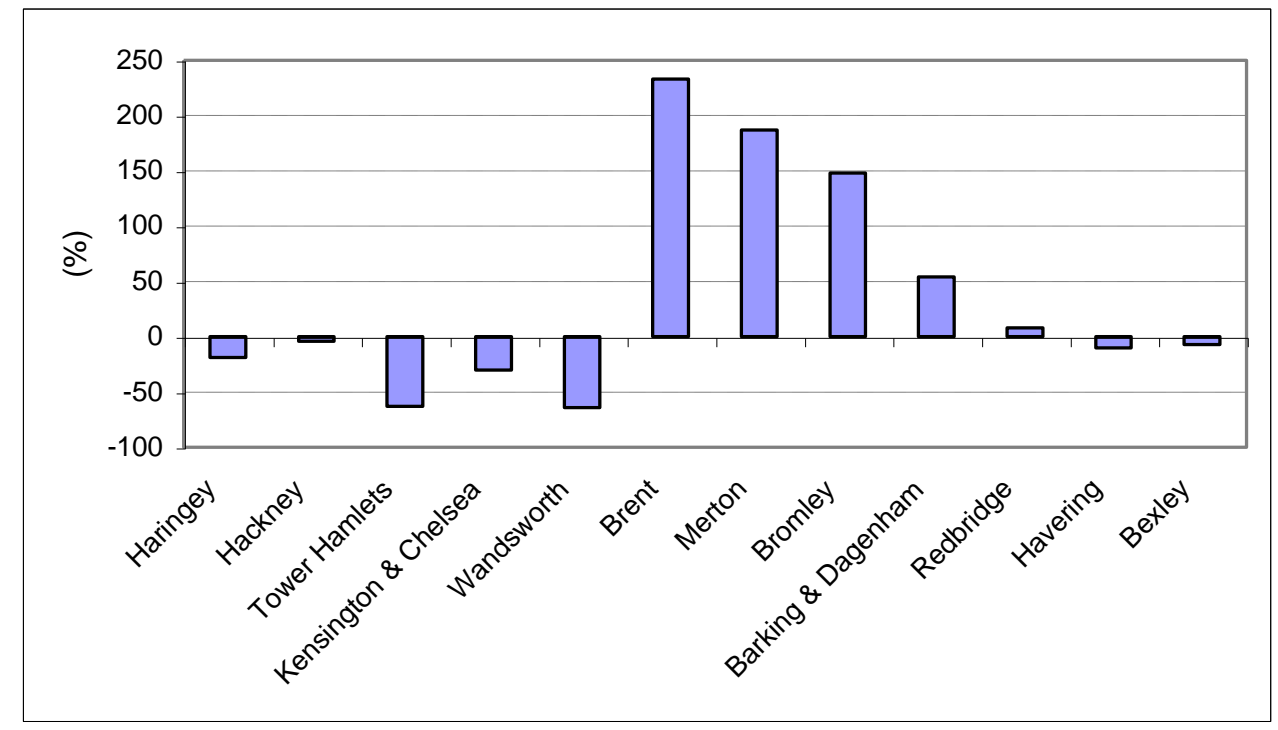

Figure 5: Percentage change in car commuting from different boroughs to the City of London

From the standard approach it is difficult to explain why commuters who previously travelled by bus would switch to the car after the introduction of the LCCS. The insight developed above, however, can help to explain this phenomenon. Thus, even if the car travel time savings are not valued more than $£ 5$, the LCCS could make the GC of car commuting fall sufficiently to motivate a switch to driving for those other-mode users whose VTTS in car travel is very elastic with respect to the level of congestion. Additionally, the precise pattern illustrated above can be conveniently explained with reference to Calfee and Winston (1998). Their empirical study, which focused specifically on estimating the VTTS of car commuters in congested conditions, found that the VTTS 'was surprisingly insensitive to travel conditions' (p. 85). The explanation given for this was that commuters most averse to congestion adjust their residential and workplace choices, inter alia, to minimise the congestion they face. This reasoning can be adapted to 
the LCCS. Thus, non-car commuters who own a car but are particularly averse to congestion are more likely to reside in outer London, so as to avoid the relatively more congested roads of central London in the other car journeys they undertake. As a result, the VTTS in car travel of these individuals is likely to be most responsive to a change in driving conditions and thus it is these individuals who are most likely to switch to using a car following the LCCS.

Let us now concentrate on the second proposition.

\section{Proposition 2}

A motorist who switches to the bus can still gain from the Scheme.

Before discussing this proposition a word should be said about the VTTS assumed for switching commuters.

Hensher and Goodwin (2004) point out that a crucial issue is whether we assign a VTTS to someone based on the mode they are moving from or mode they are moving to. The composition of the overall travel time before and after charging and between different modes is likely to be different. Mackie et al (2003b, p. 76) alert of a slightly different but closely related problem. If time benefits for existing users are valued using the average VTTS for the relevant mode, the treatment of switchers poses a problem. For example, bus time benefits will be valued in accordance with the average VTTS for buses, and car time benefits will be valued in accordance with the average VTTS for cars. On this basis, they go on to explain, switchers between modes will be treated anomalously.

For the purpose of the present study, the key issue is that for car users, the bus VTTS is higher than the car VTTS (Mackie et al, 2003b, p. 71). ${ }^{32}$ This difference may be due to mode quality attributes. For example, saving two minutes in a journey by bus may carry a higher value than saving two minutes in a journey by car. The bus may not be as clean or comfortable as the car and hence the difference in valuations.

As explained in Section 2, the average VTTS on bus tends to be about half that on rail and car. What interests us is not the difference in VTTS between modes for different users, but the difference in VTTS between modes for the same users, i.e. the switchers. Taking this

\footnotetext{
${ }^{32}$ Mackie et al (2003a, p. 71-72) consider that in principle such values should be included in generalised cost evaluation but recognise that the statistical significance of the findings is a problem and further evidence is required.
} 
on board, our mode switching analysis assumes that the car VTTS of the pre-charging car commuter is lower than his bus VTTS.

If the mode choice of commuters is governed by an effort to minimise generalised $\operatorname{costs}^{33}$, then for all those that originally travelled by car $G C_{C}^{l}-G C_{B}^{l}<0$. The change in $\mathrm{GC}$ as a result of switching to the bus, for any given commuter is

$$
G C_{C}^{l}-G C_{B}^{2}=\left(m_{C}+b_{C}^{*} t+b_{C}^{1} t_{C}^{1}\right)-\left(m_{B}+b_{B} t_{B}^{2}\right)
$$

where $t_{B}^{2}$ is the total bus journey time in period 2, after charging has been put into place.

This representation is useful in that it more formally conceptualises the standard approach of comparing the 'inconvenience of switching mode' to the valuation of the time saving which bus trips offer post-charging. Essentially 'the inconvenience of switching' can be intuitively defined as the degree to which $G C_{C}^{l}<G C_{B}^{l}$ originally. Thus, the difference between $G C_{C}^{l}$ and $G C_{B}^{2}$ is given by

$$
\begin{array}{lll}
G C_{C}^{l}-G C_{B}^{2}= & & \\
=G C_{C}^{1}-G C_{B}^{1} & + & b_{B}\left(t_{B}^{1}-t_{B}^{2}\right)= \\
=\text { 'inconvenience of switching' } & + & \text { 'valuation of bus time saving' } \\
=\left(m_{C}+b_{C}^{*} t+b_{C}^{l} t_{C}^{l}\right)-\left(m_{B}+b_{B} t_{B}^{l}\right) & + & b_{B}\left(t_{B}^{l}-t_{B}^{2}\right)
\end{array}
$$

Since we know that $t_{B}^{1}>t_{B}^{2}$, it is clearly theoretically possible that some of the commuters to the City of London will be better off (in terms of now being able to make the trip at a lower generalised cost) as a result of the LCCS, even though they incur the 'inconvenience of switching'.

Assessing the precise practical relevance of this for the LCCS would require a substantial amount of data. Thus, we would need to have values for $m_{C}, m_{B}, t$, etc. Unfortunately such data is not available. Having said this, we know that $\left(t_{B}^{1}-t_{B}^{2}\right)$ is small

\footnotetext{
${ }^{33}$ This seems reasonable for at least some commuters, since due to the regularity of a commuting trip (i.e. undertaken every weekday), benefits associated with it are likely to be consistently small across modes because of diminishing marginal utility. Thus, mode choice is more likely to be governed by an effort to minimise the generalised cost of each trip.
} 
in the case of the $\mathrm{LCCS}^{34}$. It seems likely, therefore, that most of the commuters who switched to the bus will not, even in the revised approach, become categorised as better off, in the sense that $G C_{C}^{1}<G C_{B}^{2}$.

It is, however, interesting to see what the effect would be if $\left(t_{B}^{1}-t_{B}^{2}\right)$ was larger, which is the likely implication of having a larger charging zone. Re-arranging the above expression once more, sheds light on this:

$$
\begin{aligned}
& G C_{C}^{l}-G C_{B}^{2}= \\
& G C_{C}^{1}-G C_{B}^{2}=\left(m_{C}-m_{B}\right)+\left(b_{C}^{*} t+b_{C}^{l} t_{C}^{1}-b_{B} t_{B}^{1}\right)+b_{B}\left(t_{B}^{1}-t_{B}^{2}\right)
\end{aligned}
$$

The first term $\left(m_{C}-m_{B}\right)$ is, by assumption, constant. Thus, out of those commuters who have switched to the bus and have lost out, commuters for whom $b_{B}$ is relatively large will, on average, have incurred relatively large increases in generalised costs. However, it is precisely these individuals that will benefit most from $\left(t_{B}^{1}-t_{B}^{2}\right)$ becoming larger as a result of the extension, again because they have a relatively high $b_{B}$.

Extending the zone appears to be a useful device for compensating motorists that have lost out, since, in the case of those switching from car to bus, it will, on average, likely benefit those most severely affected proportionately more.

\subsection{The problem of the distribution of VTTS}

The common denominator to the approaches in Sections 4.3 and 4.4 is that an average VTTS is used. Hensher and Goodwin (2004) alert of the dangers of such (common) practice. In their paper, they explain that the use of an average value to represent an unknown distribution of the VTTS may yield misleading results. In the case of a normal distribution, representing the distribution by its mean will not lead to erroneous conclusions and the results presented above will hold. In the case of a substantially skewed distribution on the other hand, the average will not be in the centre of the distribution, and there will be fewer drivers willing to pay the congestion charge. As a result, the car traffic reduction will

\footnotetext{
${ }^{34}$ Assuming that the average commuting trip (by car and bus) to the City of London consists of $5 \mathrm{~km}$ of travel in the CCZ, average speed data for cars and buses reveals average daily (two-way) time savings of 6.0 minutes and 3.3 minutes, respectively.
} 
be underestimated and the revenue, overestimated. The point of intersection of the two GC curves (before and after charging) will take place at a higher income level.

The VTTS distribution of the commuters to the City of London is unknown. On the one hand, since the changes in traffic and speed are taken straight from TfL reports, not knowing the VTTS distribution is not too big a problem in this case. ${ }^{35}$ On the other hand, although we know that $88.4 \%$ of the original car commuters to the City of London pay the charge, we do not know what proportion of these payers are really worse off. If a normal VTTS is assumed, then we can conclude that only those with an income higher than $£ 1400$ have seen a reduction in their GC.

\section{Conclusions}

This paper shows that the impacts of the LCCS should not be analysed from the standard approach to VTTS. This will inevitably lead to the mistaken conclusion that all those drivers who value their travel time savings below the $£ 5$ congestion charge will be regarded as losers from the Scheme.

The use of a simple expression of generalised costs per trip was shown to be a useful way to more comprehensively utilise the informational content in values of travel time savings. This revised approach leads to a different outcome in terms of impact assessment from a VTTS perspective. First, a motorist who continues to drive but values the time savings of the LCCS less than $£ 5$ can still gain from the Scheme, if the generalised cost post-charging is lower than the generalised cost pre-charging, and this is likely when the VTTS post-charging are sufficiently below the VTTS pre-charging. Second, a motorist who switches to the bus can still gain from the Scheme. Since the bus travel time post-charging will typically be lower than the bus travel time pre-charging, it is possible that the generalised cost of a trip by car pre-charging will be higher than the generalised cost of a trip by bus post-charging, even after taking into consideration the inconvenience of switching.

These findings have practical relevance in the case of the LCCS. At least some commuters to the City of London win from the Scheme although their valuation of received time savings is below $£ 5$. This however becomes less relevant the lower the distance travelled inside the CCZ. Variation in a given individual's VTTS in car travel due to the

\footnotetext{
${ }^{35}$ We are not trying to forecast what changes would take place, for which it would be useful to know the VTTS distribution.
} 
level of congestion was shown to be of paramount importance for Proposition 1, yet the precise degree of sensitivity of values of travel time savings to the level of congestion was not speculated upon. Instead a simple assumption, motivated by findings from other studies, that values of car travel time savings are $50 \%$ greater in congested conditions compared to in uncongested conditions was applied throughout, with the exception of the analysis of a the proposed extension to the CCZ. Assessing the practical relevance of Proposition 2, however, required significantly more data than was available.

The revised approach was additionally useful in illustrating the impact of having a larger CCZ. It appears that an enlargement of the zone would benefit those pre-charging car commuters that have switched to bus travel, who incur a relatively substantial increase in generalised cost.

As expected, the change in GC is very sensitive to the VTTS (and weights) assumed. That is not a limitation of this study but a note of caution that needs to be placed on almost any transport appraisal.

Charge-payer compliance costs have not been included in any of the calculations. Table 3 of the Six Months On report (TfL, 2003b) gives an estimate of $£ 15$ million per year. Although these charge-payer compliance costs are not defined in the report, they were defined in private communication with TfL as a 'notional allowance for time and effort in complying with the charge' and explained to include the time consumed in actually paying charges, such as in making the telephone call, walking to the retail outlet, or logging on to the Internet. These $£ 15$ million are an estimate of the costs incurred by all charge-payers, including private and businesses, and all paying vehicles. The total gain in travel time savings of all paying vehicles (this of course excludes buses) is estimated at $£ 135$ million per year in that same table. The annual charge-payer compliance costs therefore represent around $11 \%$ of the annual travel time benefits. If we assume that the same ratio applies for car commuters to the City of London (i.e., that their charge-payer compliance costs would amount to $11 \%$ of their travel time benefits), we can then correct the generalised cost postcharging to include charge-payer compliance costs. When we do this the generalised costs post-charging barely change. Although the difference in generalised costs post charging excluding and including charge-payer compliance costs increases with income, it never exceeds $0.14 \%$. 


\section{Acknowledgements}

The authors are grateful to Jeremy Evans, Simon Burton, Charles Buckingham, Sharon Cartwright, Ruth Excell and Karen Grayson, from Transport for London, and to Margarethe Theseira from GLA Economics for provision of data. Thanks are also due to two anonymous referees for very helpful suggestions that substantially improved the paper. Georgina Santos gratefully acknowledges support from the British Academy whilst she was at Cambridge, where most of this study was conducted, and from the Rees Jeffreys Road Fund, that supports her at Oxford, where the study was finished.

\section{Appendix}

Total daily counts of incoming and outgoing vehicles

\begin{tabular}{lcrrr}
\hline Mode & \% Change & Spring 2002 & Spring 2003 & Change \\
\hline Cars & -33 & 386,752 & 258,168 & $-128,584$ \\
Taxis & +17 & 113,007 & 131,753 & 18,746 \\
Bus \& Coaches & +18 & 26,472 & 31,253 & 4,781 \\
LGVs & -12 & 113,267 & 99,405 & $-13,862$ \\
HGVs \& Other & -12 & 31,585 & 27,878 & $-3,707$ \\
4+ Wheels & $\mathbf{- 1 8}$ & $\mathbf{6 7 1 , 0 8 3}$ & $\mathbf{5 4 8 , 4 5 6}$ & $\mathbf{- 1 2 2 , 6 2 7}$ \\
Pedal Cycles & +22 & 25,181 & 30,666 & 5,485 \\
Motor Cycles & +15 & 48,780 & 56,205 & 7,425 \\
All cycles & $\mathbf{+ 1 7}$ & $\mathbf{7 3 , 9 6 1}$ & $\mathbf{8 6 , 8 7 1}$ & $\mathbf{1 2 , 9 1 0}$ \\
Total & $\mathbf{- 1 5}$ & $\mathbf{7 4 5 , 0 4 4}$ & $\mathbf{6 3 5 , 3 2 7}$ & $\mathbf{- 1 0 9 , 7 1 7}$ \\
\hline
\end{tabular}

Source: Transport for London, data provided by request. Note: shading indicates that the mode is exempt from the toll.

\section{References}

Brownstone, D. and K.A. Small (2005), 'Valuing time and reliability: assessing the evidence from road pricing demonstrations', Transportation Research Part A: Policy and Practice, 39, pp. 279-293.

Calfee, J. and C. Winston (1998), 'The value of automobile travel time: implications for congestion policy', Journal of Public Economics, 69, pp. 83-102. 
Department for Transport (2004a), Transport Analysis Guidance: Cost Benefit Analysis, TAG Unit 3.5.4, April.

www.webtag.org.uk/webdocuments/3_Expert/5_Economy_Objective/3.5.4.htm\#2

Department for Transport (2004b), Transport Analysis Guidance: Values of Time and Operating Costs, TAG Unit 3.5.6, December.

www.webtag.org.uk/webdocuments/3_Expert/5_Economy_Objective/3.5.6.htm

Department for Transport (2005), Transport Analysis Guidance. www.webtag.org.uk

Dodgson, J., Young, J. and J. van der Veer. Paying for Road Use, Technical Report, A report to the Commission for Integrated Transport, National Economic Research Associates (NERA), London, February 2002. www.cfit.gov.uk/research/pfru/pdf/pfrutech.pdf.

Gómez-Ibáñez, J. (1992), 'The political economy of highway tolls and congestion pricing', Transportation Quarterly, 46, pp. 343-360.

Greater London Authority (2004), The Mayor's Transport Strategy Revision. GLA, London, August. www.london.gov.uk/mayor/congest/pdf/transportstrategyrevision.pdf Hau, T. (1992), 'Economic fundamentals of road pricing: A diagrammatic analysis', World Bank Policy Research Working Paper Series WPS 1070, December, Washington DC: The World Bank, pp 1-96. www.econ.hku.hk/ timhau/road_pricing.pdf

Hensher, D. (1997), 'Behavioural and resource values of travel time savings: a bicentennial update', Chapter 26 in Oum, T. H., Walter, W. G., Dodgson, J., Small,K., Hensher, D., Morrison, S., Nash, C., and W.G. Walter II (Eds.), Transport Economics: Selected Readings, Routledge.

Hensher, D. and P. Goodwin (2004), 'Using values of travel time savings for toll roads: avoiding some common errors', Transport Policy, 11, pp. 171-82.

Lam, T.C. and K.A. Small (2001), 'The value of time and reliability: measurement from a value pricing experiment', Transportation Research Part E: Logistics and Transportation Review, 37, pp. 231-251.

Litman, T. (1999), 'Using road pricing revenue: economic efficiency and equity considerations', Victoria Transport Policy Institute (http://www.vtpi.org/revenue.pdf)

Mackie, P., Wardman, M., Fowkes, A., Whelan, G., Nellthorp, J. and J. Bates (2003a), Values of travel time savings in the UK - Summary Report, Report to the Department of Transport, Institute for Transport Studies, University of Leeds, Leeds. www.its.leeds.ac.uk/working/downloads/VOTSummary.pdf 
Mackie, P., Wardman, M., Fowkes, A., Whelan, G., Nellthorp, J. and J. Bates (2003b), Values of travel time savings in the UK - Full Report, Report to the Department of Transport, Institute for Transport Studies, University of Leeds, Leeds. www.its.leeds.ac.uk/working/downloads/VOTFull.pdf

MVA Consultancy, ITS University of Leeds, and TSU University of Oxford (1987), Value of Travel Time Savings, Policy Journals, Newbery, Berks.

Richardson, H. W. and C-H. C. Bae (1998), 'The equity impacts of road pricing', Chapter 11 in Button, K. and Verhoef, E. (Eds.), 'Road Pricing, Traffic Congestion and the Environment', Edward Elgar, Lincolnshire.

Rietveld, E and E. Verhoef (1998), 'Social feasibility of policies to reduce externalities in transport', Chapter 13 in Button, K. and E. Verhoef(Eds.), 'Road Pricing, Traffic Congestion and the Environment', Edward Elgar, Lincolnshire.

Santos, G and L. Rojey (2004), 'Distributional impacts of road pricing: the truth behind the myth', Transportation, 31, pp. 21-42.

Small, K.A. (1992), Urban Transportation Economics. Hardwood Academic Publishers. Chur.

Steer Davies Gleave (2004), The Effect of Road Congestion on Rail Demand, Report to the Passenger Demand Forecasting Council, July.

Teubel, U. (2000), 'The welfare effects and distributional impacts of road user charges on commuters - an empirical analysis of Dresden', International Journal of Transport Economics, 27, pp. 231-255.

Transport for London (2002), London Travel Report. www.tfl.gov.uk/tfl/reports_library_stats.shtml.

Transport for London (2003a), Central London Congestion Charging Scheme: Three Months On, TfL, London, June. www.tfl.gov.uk/tfl/pdfdocs/congestion_charging/ccthree-month-report.pdf.

Transport for London (2003b), Congestion Charging: Six Months On. TfL, London, October. www.tfl.gov.uk/tfl/downloads/pdf/congestion-charging/cc-6monthson.pdf.

Transport for London (2003c), Impacts Monitoring Programme: First Annual Report. TfL, London, June. www.tfl.gov.uk/tfl/cc_monitoring.shtml.

Transport for London (2004a), Congestion Charging - Update on scheme impacts and operations. TfL, London, February. www.transportforlondon.gov.uk/tfl/downloads/ pdf/congestion-charging/cc-12monthson.pdf. 
Transport for London (2004b) Congestion Charging Central London - Impacts Monitoring:

Second Annual Report. TfL, London, April. www.tfl.gov.uk/tfl/cclondon/cc_monitoring2nd-report.shtml

Transport for London (2004c). Annex E: Report to the Mayor

Economic Assessment, High Level Economic Impact Assessment of the Draft Transport Strategy Revision: Central London Congestion Charging, TfL, London, July. http://www.tfl.gov.uk/tfl/downloads/pdf/congestion-charging/e-economicassessment.pdf

Transport for London (2005), Central London Congestion Charging Scheme - Impacts Monitoring: Summary Review January 2005. TfL, London, January. Www.tfl.gov.uk/tfl/cclondon/pdfs/impacts-monitoring-report-january-2005.pdf

Wardman, M. (2001), 'A review of British evidence on time and service quality valuations', Transportation Research Part E: Logistics and Transportation Review, 37 , pp. 107-128. 